\title{
BREVES NOTAS SOBRE O ARRANJO MACROECONÔMICO PARA O ENFRENTAMENTO DA CRISE DA COVID-19 NA CHINA
}

Gilberto Libânio ${ }^{1}$

Resumo: Este artigo busca apresentar as principais medidas de política macroeconômica adotadas pela China em resposta à crise econômica provocada pela pandemia de COVID-19. O argumento central do trabalho é que não é possível compreender o processo de combate à pandemia e as medidas de recuperação da economia chinesa, sem se considerar o arcabouço institucional de atuação do Estado e de condução da política macroeconômica. Conclui-se que atuação estratégica do governo chinês apresenta bons resultados na recuperação da atividade econômica, mas também pavimenta uma trajetória favorável de desenvolvimento a longo prazo.

Palavras-chave: China. COVID-19. Política macroeconômica.

\section{BRIEF NOTES ON THE MACROECONOMIC ARRANGEMENT FOR COPING WITH THE COVID-19 CRISIS IN CHINA}

Abstract: This paper presents the main macroeconomic policy measures adopted by China in response to the economic crisis caused by the COVID-19 pandemic. The main argument of the paper is that it is not possible to understand the process of combating the pandemic and the measures for the recovery of the Chinese economy, without considering the institutional framework of State action and the conduct of macroeconomic policy. We conclude that the Chinese government's strategic performance presents good results in the recovery of economic activity, but it also paves the way for a favorable long-term development path.

Keywords: China. COVID-19. Macroeconomic policy.

\section{BREVES NOTAS SOBRE EL ARREGLO MACROECONÓMICO PARA ENFRENTAR LA CRISIS DEL COVID-19 EN CHINA}

Resumen: Este artículo busca presentar las principales medidas de política macroeconómica adoptadas por China en respuesta a la crisis económica provocada por la pandemia COVID-19. El argumento central del trabajo es que no es posible comprender el proceso de combate a la pandemia y las medidas para la recuperación de la economía china, sin considerar el marco institucional de la acción del Estado y la conducción de la política macroeconómica. Se concluye que el desempeño estratégico del gobierno chino presenta buenos resultados en la recuperación de la actividad económica, pero también allana el camino para una senda de desarrollo favorable en el largo plazo.

Palabras clave: China. COVID-19. Política macroeconómica.

\footnotetext{
1 Universidade Federal de Minas Gerais, Departamento de Ciências Econômicas, Belo Horizonte, Brasil, gilberto@cedeplar.ufmg.br, https://orcid.org/0000-0002-4583-4346. O autor agradece o financiamento da FAPEMIG.
} 


\section{Introdução}

O ano de 2020 entrará para a história como o ano de irrupção da grave crise sanitária e econômica provocada pela epidemia de COVID-19 em escala global. A interrupção de inúmeras atividades econômicas, em virtude da estratégia de isolamento social necessária para combater a disseminação do Corona Vírus, teve como consequência uma expressiva desaceleração das taxas de crescimento econômico tanto nos países centrais como nos países em desenvolvimento, levando na maior parte dos países a um cenário de forte recessão.

As respostas à crise econômica de 2020, no que se refere à adoção de políticas macroeconômicas, foram distintas entre os vários países, tanto na escolha dos instrumentos, como na magnitude das ações e no timing para sua implementação. A China, em particular, tem sido apontada como exemplo na adoção de políticas bem-sucedidas, seja no enfrentamento da epidemia em si, seja nas ações de estímulo à retomada do nível de atividade econômica.

O objetivo deste artigo é apresentar e discutir as políticas macroeconômicas adotadas pelo governo da China como resposta ao contexto da pandemia de COVID-19. O argumento central a ser apresentado é que não é possível compreender o processo de combate à pandemia e as medidas de recuperação da economia chinesa, sem se considerar o arcabouço institucional de atuação do Estado e de condução da política macroeconômica. Em outras palavras, sustenta-se aqui que a configuração do Estado chinês - incluindo sua estrutura fiscal, seu arcabouço de política monetária, suas instituições financeiras públicas, e sua visão estratégica de desenvolvimento econômico a longo prazo - o qualifica de modo particularmente favorável para a adoção de medidas eficazes de estímulo para a recuperação pós-pandemia.

O restante do artigo está estruturado da seguinte forma. A próxima seção descreve brevemente o arcabouço geral de política econômica da China, entendido como um conjunto de instrumentos coordenados de atuação em favor do desenvolvimento econômico do país, e mostra como tais instrumentos foram utilizados de forma exitosa após a crise financeira global de 2008-2009. Em seguida, serão apresentadas as principais medidas de enfrentamento da crise econômica associada à pandemia de COVID-19, particularmente no primeiro semestre de 2020, e discutidas - ainda que de forma preliminar - seus resultados já observados, no que se refere à evolução das principais variáveis macroeconômicas no período 
recente. Por fim, a última seção resume os principais resultados da análise e apresenta algumas considerações finais.

\section{Política Macroeconômica e o Crescimento da Economia da China}

Esta seção descreve a atuação da política macroeconômica na China, a partir de duas referências teóricas centrais: 0 Keynesianismo e 0 Novo Desenvolvimentismo. A associação com o Keynesianismo se justifica a partir do reconhecimento de que a política macroeconômica é utilizada na China como instrumento de sustentação da demanda agregada e como redutor de incertezas frente à trajetória futura da economia - argumento que será amparado na exposição de exemplos concretos de atuação do Estado, como na crise financeira de 20082009 e na atual crise econômica associada à pandemia de COVID-19. No que se refere à associação com o Novo Desenvolvimentismo (Bresser-Pereira, 2016), defende-se aqui que a condução da política macroeconômica na China se insere em uma estratégia nacional de desenvolvimento e se implementa de forma coordenada a outras políticas, particularmente à política industrial.

Keynes (1936) destaca a importância da política macroeconômica como instrumento de correção de insuficiências de demanda agregada. Em termos concretos, Keynes defende que o governo deveria implementar projetos de investimento público, que não competissem com o setor privado, mas que, ao contrário, estimulassem o setor privado a investir por criar um ambiente favorável a partir da manutenção de um patamar estável de demanda agregada ao longo do tempo (Carvalho, 1997, p. 40). Desta forma, o Estado teria importante papel na redução das incertezas associadas à insuficiência de demanda efetiva, elemento particularmente relevante nas decisões de investimento.

\footnotetext{
"The particular character of Keynes's policy proposals consists in the definition of a set of measures designed to reduce or socialize the uncertainties that surround economic decisions and to boost aggregate demand through state intervention when private demand failed" (Carvalho, 1997, p. 41).
}

Keynes sugere ainda que, para implementar políticas fiscais anticíclicas, o governo deveria manter dois orçamentos fiscais separados: um para gastos correntes regulares do governo, outro para gastos discricionários, particularmente em investimentos. Este orçamento discricionário seria por excelência o instrumento de política fiscal anticíclica, e deveria abarcar atividades que poderiam ser ampliadas ou reduzidas de acordo com o ritmo da demanda agregada. Neste caso, 
Keynes sugere que o governo (inclusive a nível local) mantivesse projetos de investimento "na gaveta", prontos para serem iniciados perante sinais de desaceleração da demanda agregada (Carvalho, 1997).

Por outro lado, uma das principais características da visão de Keynes é a natureza abrangente da gestão macroeconômica e a necessidade de coordenação entre as diferentes políticas macroeconômicas. Neste sentido, a definição de instrumentos específicos de política monetária, fiscal e cambial seria tão importante quanto a preocupação de que tais políticas fossem conduzidas de forma coordenada, de modo a não gerarem resultados conflitantes, nem tampouco emitirem sinais contraditórios para o público.

Cabe ainda reforçar que o planejamento das ações do governo no campo da política macroeconômica tem um papel não apenas de sinalização ao setor privado, mas também de construção do futuro, dada a capacidade do Estado em direcionar a trajetória futura da economia. Nas palavras de Carvalho (1997, p. 41):

\footnotetext{
"The possibility of planning, in the sense of preparing intervention plans to compensate for the eventual lack of private investments, was enhanced, in Keynes's view, by the fact that government is not just another guess-maker as to future trends but is, to a large extent, a builder of the future, through its power to mobilize resources and to influence aggregate demand".
}

No que se refere à condução da política macroeconômica na China, é possível identificar alguns dos elementos associados à visão Keynesiana descrita anteriormente. Em particular, se fazem presentes no caso chinês tanto o caráter de sustentação da demanda agregada atribuído à política macroeconômica, quanto sua condução de maneira coordenada entre os diferentes instrumentos utilizados.

Naughton (2018) caracteriza a política macroeconômica da China no século XXI como "super-Keynesiana", na medida em que o país tem utilizado de forma ativa e coordenada os instrumentos de política fiscal, monetária e cambial disponíveis para incentivar o obtenção de elevadas taxas de crescimento econômico, liderado na maior parte do tempo pelo investimento e pelas exportações.

Segundo Naughton (2018, p. 478),

\footnotetext{
"Macroeconomic policy has been characterized by a prompt and mutually consistent use of Keynesian instruments for macroeconomic management. Monetary, fiscal, and exchange rate policy have been used together to achieve desired outcomes. Moreover, policy has consistently stimulated increases in aggregate demand components in order to keep growth high."
}

O Novo Desenvolvimentismo (Bresser-Pereira, 2016), por sua vez, também representa um referencial teórico interessante para a leitura do caso chinês. Cabe 
destacar aqui algumas de suas proposições centrais no que tange à condução da política macroeconômica, de modo a avaliar a atuação do Estado na China à luz dessas considerações. Em primeiro lugar, defende-se que a política macroeconômica esteja inserida em uma estratégia nacional mais ampla de desenvolvimento econômico, e que seja implementada de forma coordenada em relação a outras políticas, como a política industrial e a política comercial. Quanto à condução de cada política macroeconômica específica, a visão NovoDesenvolvimentista sugere que a política fiscal tenha como prioridade garantir a realização de investimentos públicos e que, embora se deva buscar o equilíbrio fiscal ao longo do tempo, a geração de déficits temporários é aceitável e muitas vezes necessária para viabilizar as ações do governo essa área. A política monetária, por seu turno, deve ser conduzida de forma a garantir a manutenção de taxas de juros moderadas ao longo do tempo, de modo a não penalizar excessivamente o financiamento das despesas em consumo e, principalmente, investimento privado. Em relação à política cambial, defende-se que a taxa de câmbio seja flutuante, mas administrada, e mantida em patamares competitivos, para estimular as exportações e permitir o avanço na sofisticação da estrutura produtiva e da pauta exportadora. Ainda sobre o setor externo, a perspectiva NovoDesenvolvimentista defende a manutenção de saldos positivos em conta corrente ao longo do tempo e a utilização de controles de capitais sempre que necessário, para auxiliar no cumprimento das metas para a taxa de câmbio.

Bresser-Pereira, Jabbour e De Paula (2020) buscam analisar a evolução da economia da China pós-1978 a partir de uma abordagem novo-desenvolvimentista. Segundo esses autores, a trajetória percorrida pela China nas últimas décadas e suas estratégias de política econômica são coerentes com as proposições defendidas pelo Novo Desenvolvimentismo, e podem ser observadas nas altas taxas de investimento, na geração de superávits em conta corrente, e na manutenção de uma taxa de câmbio competitiva. Destaca-se também a adoção de políticas industriais coordenadas e complementares à condução da política macroeconômica, com forte presença do Estado em setores estratégicos, de modo a permitir a conformação de uma trajetória de crescimento com mudança estrutural, liderada pelos investimentos e pelas exportações.

As principais conclusões da análise de Bresser-Pereira, Jabbour e De Paula (2020) sobre o caso chinês podem ser resumidas como se segue: 
In sum, the Chinese development strategy can be described as a combination of the following: (1) the presence of institutional innovation cycles that, by strategically recasting the state's role, enabled continuity solutions for the development process; (2) a foreign exchange policy associated with a current-account surpluses policy and controlled capital flows to keep the foreign exchange rate competitive (...); (3) a low interestrate policy that discourages capital inflows and stimulates, together with rising real wages, the role of consumption as a component of demand; (4) combination of a correct productive density strategy on the exports front and high domestic investment rates; and (5) significant state control over large government-owned assets in strategic sectors and the financial system. (Bresser-Pereira, Jabbour e De Paula, 2020, p. 281-2).

A análise empreendida neste trabalho sugere que a condução da política macroeconômica na China está coordenada com objetivos amplos de desenvolvimento nacional. Cabe então perguntar qual o arcabouço institucional presente para a implementação de tal estratégia de desenvolvimento. Em outras palavras, busca-se examinar brevemente as características da estrutura fiscal, a institucionalidade da política monetária e os instrumentos de condução da política cambial que permitam a adoção das referidas políticas, em linha com um projeto mais amplo de desenvolvimento, ao mesmo tempo em que permitem uma atuação incisiva e eficaz em momentos de crise, como ocorreu em 2008 e está ocorrendo novamente em 2020.

\section{Politica Fiscal}

O arcabouço fiscal na China passou por reformas sucessivas ao longo do tempo. Em particular, a estrutura atual está baseada em uma importante reforma fiscal ocorrida em meados dos anos 1990, que reverteu uma trajetória declinante da participação das receitas fiscais no PIB, aumentou a centralização da arrecadação tributária e estabeleceu as bases para a adoção de políticas fiscais contra-cíclicas no país.

Em 1994 e 1995, as receitas tributárias (incluindo o governo central e os governos subnacionais) alcançaram seu menores valores desde o início das reformas de 1978 - pouco acima de 10\% do PIB. A reforma fiscal de 1994 contou com três componentes centrais: a criação de novos impostos (como um imposto sobre valor adicionado e um imposto sobre lucros), um novo sistema de competências e distribuição de impostos, e uma nova agência tributária do governo central (Naughton, 2018). A reforma foi bem sucedida em recuperar a capacidade de arrecadação do Estado chinês, e as receitas tributárias se elevaram gradualmente 
na segunda metade dos anos 1990 e na primeira década do século XXI, tendo se estabilizado entre $20 \%$ e $22 \%$ do PIB desde 2010.

A despeito do crescimento das receitas, o setor público chinês tem obtido déficits fiscais sucessivos, uma vez que as despesas fiscais também se elevaram em ritmo semelhante ao das receitas, com destaque para os gastos em educação, saúde, previdência e segurança pública. Entre 2001 e 2018, em apenas um ano (2007) o resultado fiscal foi superavitário, e em apenas dois anos (2006 e 2008) o déficit público foi inferior a $1 \%$ do PIB. Já em 2009 o déficit volta a subir, em virtude da expansão fiscal adotada em resposta à crise financeira global de 2008 (Figura 1). Nos últimos anos, o déficit público da China tem se expandido - atingindo 4\% do PIB - devido principalmente à menor expansão das receitas tributárias associada à desaceleração das taxas de crescimento econômico verificadas desde 2013.

Gráfico 1 - China - Déficit Fiscal como Percentual do PIB (2001-2018)

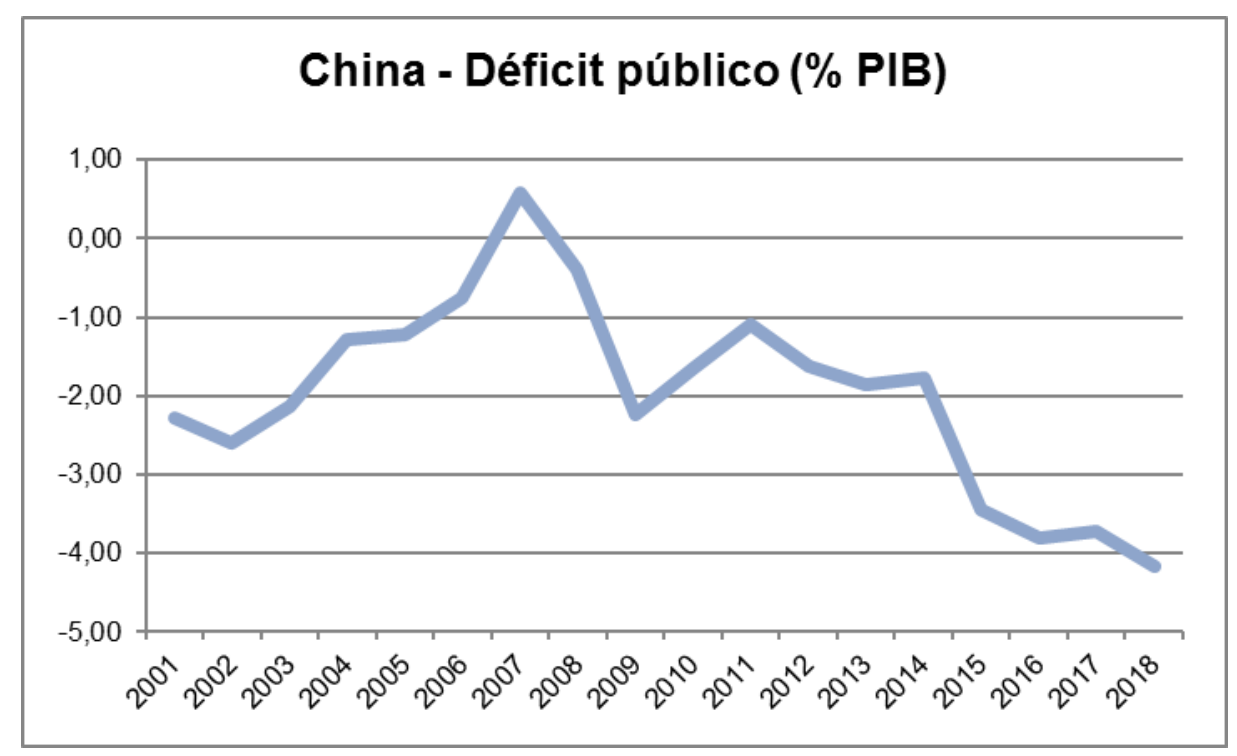

Fonte: National Bureau of Statistics (2019)

A estrutura fiscal chinesa está organizada em cinco níveis hierárquicos: governo central, províncias, prefeituras, condados e distritos (Jia, Guo and Zhang, 2014) ${ }^{2}$. Uma das principais características do sistema chinês é a grande descentralização da despesa pública, estruturada a partir de um processo decisório hierárquico. Isto é, cabe ao governo central estabelecer as linhas mestras da política fiscal, ao passo que sua operacionalização se define por meio de regras de repartição das receitas dos entes sub-nacionais em direção aos de nível

\footnotetext{
${ }^{2}$ Segundo dados oficiais, a China se divide em 333 prefeituras, 2851 condados e 39945 distritos (National Bureau of Statistics, 2019).
} 
imediatamente inferior. Assim, as províncias definem regras de repartição para as prefeituras, que, por sua vez, as definem em relação aos condados (Jia, Guo and Zhang, 2014).

Em linhas gerais, a despesa orçamentária do governo central inclui a provisão de alguns serviços públicos, gastos com defesa nacional e relações exteriores, ciência e tecnologia, gastos em infraestrutura, políticas de desenvolvimento regional, e despesas associadas à regulação macroeconômica. Os dispêndios dos governos locais incluem a provisão de alguns serviços públicos, segurança pública, programas voltados para a agricultura, gastos em educação, saúde, seguridade social e outros programas sociais implementados localmente (National Bureau of Statistics, 2019).

Por outro lado, há um relativo desequilíbrio entre a capacidade de arrecadação e a distribuição do gasto entre o governo central e os governos subnacionais. Ou seja, os governos locais não tem capacidade de arrecadação compatível com suas necessidades de despesa, e por isso dependem fortemente de transferências de recursos do governo central. Tal característica se exacerbou ao longo das últimas duas décadas pois, entre 2001 e 2018, se expandiu a parcela do gasto público executado a nível local, se estabilizando em torno de $85 \%$ do total no período mais recente. As receitas tributárias locais, por seu turno, tiveram crescimento mais modesto, e representam pouco mais de 50\% da arrecadação total (figura 2).

Gráfico 2 - China - Receitas tributárias e despesas a nível local, como porcentagem do total (2001-2018)

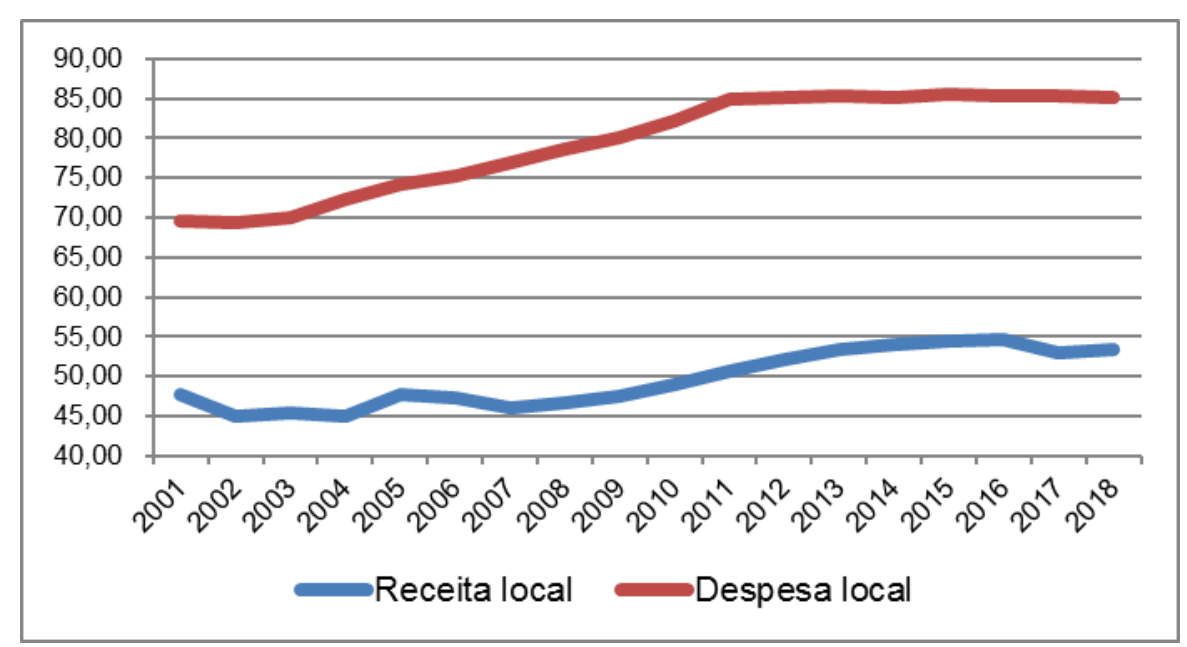

Fonte: National Bureau of Statistics (2019)

A partir de 2013-2014, foi proposta uma nova rodada de reformas do sistema fiscal, que prevê a ampliação de impostos diretos, regras mais claras para as 
transferências governamentais, e novos requerimentos para endividamento a nível local, entre outras medidas (Wong, 2016). Tais reformas buscam corrigir alguns dos desequilíbrios do arcabouço fiscal chinês e podem significar um realinhamento nas relações entre governo central e governos locais, mas sua implementação ainda está em andamento (Naughton, 2018).

\section{Políticas Monetária e Cambial}

$\mathrm{Na}$ China, as políticas monetária e cambial são conduzidas pelo Banco Central (Banco do Povo da China - PBoC), cujas funções foram legalmente definidas em 2003. O PBoC exerce atividades típicas de bancos centrais, como formulação e implementação da política monetária, emissão da moeda nacional, administração das reservas cambiais, condução da política cambial, regulação dos mercados financeiros e prevenção de riscos sistêmicos, garantindo o normal funcionamento dos sistemas de pagamentos e liquidação, entre outros (Libanio, 2015).

Cabe notar que o PBoC não é independente, sendo subordinado ao Conselho de Estado. Assim, o Banco Central segue as diretrizes de política macroeconômica definidas pelo governo central, em linha com as metas anuais de crescimento do PIB.

O objetivo da política monetária da China - conforme declarado no site do PBoC - é "manter a estabilidade do valor da moeda e, assim, promover o crescimento econômico". Na prática, o Conselho de Estado atribuiu ao PBoC os objetivos gerais de estabilidade de preços, crescimento do produto e emprego, estabilidade financeira, e equilíbrio externo.

Para atingir seus múltiplos objetivos, o PBoC usa, a seu critério, diferentes instrumentos, como operações de mercado aberto, alteração nos coeficientes de reservas compulsórias e a definição de várias taxas de juros, como a Standing Lending Facility (SLF), que funciona como um teto para a taxa de juros de mercado e a Medium-Term Lending Facility (MLF), para crédito de médio prazo a instituições financeiras.

A estratégia de política monetária da China tem sido historicamente baseada em metas monetárias, por meio do uso de controles quantitativos em empréstimos bancários e outros instrumentos, como reservas compulsórias. O PBoC define metas para as taxas de crescimento do M2 e do crédito bancário que são consistentes com 
seus objetivos de política e tem uma série de instrumentos à sua disposição para atingir suas metas de oferta de moeda e crescimento de crédito. Operações de mercado aberto e mudanças na taxa de reservas compulsórias para bancos comerciais têm sido as principais ferramentas com as quais o PBoC afeta a oferta de moeda e as condições do mercado em geral (Chen, Chen and Gerlach, 2013).

Além disso, a política monetária inclui medidas menos convencionais, como crédito direto a taxas de juros subsidiadas para os bancos de desenvolvimento da China, e a chamada "orientação de janela" - quando o PBoC influencia a estrutura de empréstimos bancários por meio de intervenções informais junto aos bancos comerciais. Cabe ainda destacar a importância dos bancos comerciais públicos e dos bancos de desenvolvimento na China, que são também utilizados como acessórios para a implementação da política monetária e colocados a serviço da estratégia de desenvolvimento do país.

No que se refere à política cambial, sua condução também está alinhada com objetivos mais amplos de desenvolvimento econômico. Pode-se dizer que o câmbio na China é administrado, isto é, o PBoC intervém ativamente no mercado cambial com o objetivo de manter a taxa de câmbio da moeda nacional dentro de limites predeterminados. Particularmente entre meados dos anos 1990 e meados dos anos 2000, a taxa de câmbio foi mantida fixa e relativamente desvalorizada, de modo a estimular as exportações e contribuir para a geração de superávits em conta corrente.

Cabe ainda notar que a China nunca adotou políticas abrangentes de liberalização financeira externa, tendo sempre mantido mecanismos de controle de capital. Desta forma, foi capaz de manter controle sobre sua taxa de câmbio sem abrir mão de sua autonomia de política monetária.

Em resumo, o PBoC define as políticas monetária e cambial de maneira discricionária, em linha com as metas econômicas gerais definidas pelo governo central, incluindo objetivos reais e nominais. Neste sentido, uma política monetária discricionária e uma política de câmbio competitivo tem sido elementos fundamentais para garantir a estabilidade de preços, o crescimento do PIB e a mudança estrutural da economia chinesa. 
A política macroeconômica na China após a crise financeira de 2008

No segundo semestre de 2008, o governo chinês atuou rapidamente para combater os efeitos da crise financeira internacional - com a adoção de um amplo conjunto de políticas macroeconômicas expansionistas, acompanhadas por medidas de política industrial - reconhecendo que a dependência da economia chinesa das exportações poderia trazer vulnerabilidades em um momento de recessão global.

No campo da política fiscal, foi adotado um programa de estímulos no valor de $¥ \$ 4$ trilhões (cerca de US\$600 bilhões, ou 12\% do PIB chinês). A principal destinação desses gastos foi em infraestrutura de transportes - ferrovias, rodovias, transporte público urbano, aeroportos - com $45 \%$ do total. Foram também alocados recursos ( $25 \%$ do total) para a reconstrução da província de Sichuan, que havia sido atingida por um terremoto em maio de 2008, bem como para investimentos em infraestrutura rural, preservação ambiental, habitação popular, e inovação tecnológica.

Segundo Sun and Fu (2012), as principais fontes de financiamento dessa expansão fiscal foram: (i) recursos do governo central, para a concessão de empréstimos subsidiados, e injeção direta de recursos em projetos de investimento; (ii) emissão de títulos públicos para financiar a expansão do déficit público em cerca de 2 pontos percentuais do PIB (como visto na seção anterior); (iii) emissão de títulos do governo central em favor dos governos locais; (iv) empréstimos bancários para os governos locais, como principal fonte de financiamentos dos investimentos a nível local. Neste caso, cabe destacar a importância dos bancos comerciais públicos - os maiores bancos da China - que foram instruídos pelo governo central a expandir rapidamente o crédito, e dos bancos de desenvolvimento - notadamente 0 China Development Bank, que executou um programa de empréstimos a longo prazo com taxas de juros moderadas ou mesmo subsidiadas (Naughton, 2018).

No que se refere à política monetária, a resposta foi rápida e incisiva. As taxas de juros foram levadas aos patamares mínimos da série histórica, a taxa de reservas compulsórias dos bancos foi reduzida, e foram removidas barreiras quantitativas para a concessão de crédito bancário. Como consequência, observa-se expressiva elevação da liquidez na economia no período: apenas no primeiro semestre de 2009, a expansão dos empréstimos bancários foi de aproximadamente $¥ \$ 7,4$ trilhões (cerca de $23 \%$ do PIB) - valor superior ao observado nos anos de 2006 e 2007 somados (Sun and Fu, 2012). 
Tais medidas de política fiscal e monetária foram acompanhadas por um conjunto de outras medidas, de política cambial, comercial e industrial, confirmando a característica coordenada das políticas econômicas na China, como destacado anteriormente. Neste caso, pode-se mencionar políticas de apoio ao pequenas e médias empresas (como 0 adiamento ou suspensão nos pagamentos das contribuições sociais), redução dos juros para financiamento habitacional, e elevação na restituição de impostos de exportação para setores intensivos em mãode-obra, de modo a estimular sua competitividade internacional.

Cabe ainda destacar a velocidade com que as medidas foram adotadas e os projetos de investimento foram implementados. Tal resultado se deveu principalmente à estrutura política centralizada e hierárquica, na qual as orientações do governo central eram prontamente disseminadas pelas outras esferas de governo, e as ações eram rapidamente implementadas com o uso dos instrumentos disponíveis. Além do já mencionado papel dos bancos públicos na transmissão da política monetária e creditícia, deve-se também destacar o papel dos governos locais na implementação dos projetos de investimento associados ao estímulo fiscal - que se aproxima da proposição de Keynes (apresentada anteriormente neste artigo) de que o governo deveria acelerar a execução de projetos pré-concebidos em momentos de desaceleração da economia. De acordo com Naughton (2018, p. 473):

"A typical local government has a queue of projects waiting to be approved. When a negative shock hit the system, local governments could pull a project "off-the-shelf", more or less ready-made, so the response to the increasing availability of credit was rapid".

Em suma, a rápida resposta e a adoção de um amplo conjunto de políticas coordenadas de estímulo à economia foi essencial para amenizar os efeitos adversos da crise financeira global de 2008: a China foi a única entre as maiores economias do planeta a não sofrer uma recessão em 2009, e também foi a que mais fortemente se recuperou após a crise ${ }^{3}$. A orientação das políticas foi clara e coordenada, o que contribuiu para a redução de incertezas e funcionou como um guia para as expectativas dos agentes econômicos. A ênfase nos investimentos em infraestrutura foi adequada como política anticíclica mas também contribuiu para o desenvolvimento da economia chinesa a longo prazo. Por fim, a disponibilidade dos instrumentos adequados para a condução das políticas fiscais, monetárias,

\footnotetext{
${ }^{3}$ A taxa de crescimento do PIB real nos anos 2008, 2009 e 2010 foi de 9,7\%, 9,4\% e 10,6\%, respectivamente. Em 2009, ano mais agudo da crise internacional, o declínio das exportações chinesas contribuiu com uma queda de 4p.p. no PIB, que foi compensada principalmente pela expansão dos investimentos, que contribuiu com uma elevação de 8,1p.p. no PIB da China daquele ano.
} 
comerciais e industriais assegurou a continuidade de sua implementação e foi determinante para a obtenção dos bons resultados que se seguiram.

A experiência chinesa pós-crise de 2008 é um precedente importante para se entender e se analisar as respostas à crise econômica provocada pela pandemia de COVID-19, como se descreverá na próxima seção.

\section{O Combate à Crise Econômica e a Recuperação Chinesa Pós-Pandemia}

A necessidade de isolamento social e a imposição de "lockdown" em algumas regiões trouxe expressivos efeitos adversos sobre a atividade econômica na China. Por um lado, representou o fechamento temporário de fábricas e a interrupção de cadeias globais de valor. Por outro, significou queda acentuada na demanda agregada, devido ao impacto da incerteza e do declínio das expectativas de renda futura sobre consumo e investimento.

Tais efeitos resultaram em um declínio de $10 \%$ no PIB real da China no primeiro trimestre de 2020, em relação ao trimestre anterior. No mesmo período, foram também observados fortes impactos negativos na produção industrial, na formação bruta de capital fixo, nas vendas a varejo, nas exportações e no índice de confiança empresarial $^{4}$ (Funke and Tsang, 2020). Ao final do primeiro trimestre de 2020, as projeções de crescimento para a economia chinesa no ano eram de 1,2\%, segundo o $\mathrm{FMI}$, e 2,3\% segundo o Banco Mundial - em comparação a um crescimento observado de 6,1\% em 2019.

Assim como observado na crise financeira internacional de 2008-2009, o governo chinês respondeu rapidamente à crise de 2020 com um conjunto abrangente de medidas de incentivo à atividade econômica. Mais além dos efeitos imediatos da crise, respondia-se também ao objetivo de evitar uma onda de falências e demissões em massa, que levariam a um aprofundamento da recessão e dificultariam a posterior recuperação da economia. Em linhas gerais, o governo chinês afirmou buscar estabilizar a economia em seis áreas: emprego, finanças, comércio exterior, investimento externo, investimento doméstico, e expectativas de mercado.

Em um primeiro momento, grande atenção foi dedicada a apoiar os setores e atividades relacionados ao combate ao Corona Vírus, incluindo equipamentos médicos e serviços de saúde, bem como os setores ou atividades mais fortemente

${ }^{4}$ OECD Business Confidence Index: https://data.oecd.org/leadind/business-confidence-index-bci.htm 
afetados pela epidemia, como transporte e turismo. Tal apoio se deu por meio de medidas fiscais, como a redução ou adiamento de impostos, e creditícias, como o acesso a crédito subsidiado.

No que se refere à política fiscal, foi anunciada a expansão do déficit público em $¥ \$ 1$ trilhão, somada à emissão de $¥ \$ 1$ trilhão em títulos de tesouro, totalizando $¥ \$ 2$ trilhões em incentivos fiscais. $85 \%$ desse valor foi diretamente destinado aos governos locais (prefeituras e condados), principalmente para a implementação de projetos de investimento. O restante - cerca de $¥ \$ 300$ bilhões - seria usado para financiar as reduções e isenções de taxas e impostos previstas para este ano.

Mais especificamente, uma série de medidas tributárias foi anunciada para sustentar a produção e o emprego, incluindo a isenção temporária do imposto sobre valor adicionado para pequenas e médias empresas, isenção ou redução das contribuições sociais, redução das tarifas de eletricidade, entre outras (Huang et al., 2020).

Cabe notar que o volume de incentivos fiscais - como proporção do PIB - é claramente inferior ao observado em resposta à crise de 2008. Segundo o governo chinês, ao invés de recorrer a um estímulo massivo liderado pelo governo para sustentar a retomada da atividade econômica, a China está buscando investimentos mais direcionados em projetos que facilitem a inovação e corrijam deficiências no desenvolvimento econômico e social.

Em particular, isto significa utilizar não apenas os instrumentos de política fiscal, mas também outros instrumentos, para apoiar investimentos em infraestrutura. Grandes projetos nas áreas de energia, transporte e $\mathrm{Tl}$ (com destaque para redes $5 \mathrm{G}$ ) foram iniciados, financiados por títulos dos governos sub-nacionais ${ }^{5}$.

Assim como em 2008, a China está mirando em novos projetos de infraestrutura para contrabalançar os efeitos negativos da crise da COVID-19. No entanto, se há pouco mais de uma década os investimentos focavam principalmente a construção de uma infraestrutura básica de transportes, no momento atual as prioridades são os investimentos em setores tecnologicamente avançados - em comunicações, comércio digital, veículos elétricos, energias limpas, etc. - de modo a pavimentar o caminho para o desenvolvimento da economia chinesa a longo prazo.

Quanto à política monetária, cabe destacar inicialmente o anúncio feito pelo Banco do Povo da China de que adotaria um conjunto de políticas monetárias para

\footnotetext{
5 Vinte e uma províncias (ou regiões com status equivalente) reportaram novos projetos de investimento associados à construção de redes 5G.
} 
prover liquidez ao mercado, garantir o suprimento de crédito e evitar instabilidade financeira ${ }^{6}$. Tais medidas incluem operações de mercado aberto, redução nas taxas de juros dos empréstimos do banco central, alteração nas reservas compulsórias dos bancos comerciais, e o direcionamento das expectativas de mercado.

Ao longo do primeiro trimestre de 2020, uma série de ações de política monetária foram tomadas de modo a promover os objetivos anunciados no início da crise. Funke and Tsang (2020) destacam vinte e uma dessas medidas entre os meses de fevereiro, março e abril, e estimam que a injeção extraordinária de liquidez no período foi cerca de $¥ \$ 3,6$ trilhões.

As primeiras respostas da economia chinesa aos esforços de contenção da epidemia e às políticas voltadas para recuperação da atividade econômica foram rápidas e favoráveis, assim como havia ocorrido em 2008-2009. No segundo trimestre de 2020, observa-se elevação de $11,5 \%$ do PIB real (que havia caído 10\% no trimestre anterior). Outros indicadores da atividade econômica também tem mostrado recuperação nos últimos meses, como o consumo de energia elétrica, a produção industrial e a importação de matérias-primas.

As políticas anunciadas e adotadas também foram bem sucedidas em conter a instabilidade financeira. $O$ declínio observado no mercado acionário chinês foi inferior ao de outras bolsas de valores pelo mundo. O diferencial de juros sobre os títulos públicos da China também foi relativamente limitado, o que sugere que o mercado nutriu expectativas otimistas sobre a capacidade de atuação do governo chinês e sobre as perspectivas de recuperação da economia.

\section{Considerações Finais}

Este artigo procurou descrever brevemente as políticas macroeconômicas adotadas pelo governo da China em resposta à epidemia de COVID-19. O argumento central do trabalho é que não é possível compreender o processo de combate à pandemia e as medidas de recuperação da economia chinesa, sem se considerar o arcabouço institucional de atuação do Estado e de condução da política macroeconômica.

Neste sentido, cabe destacar alguns elementos cruciais que caracterizam o caso da China: (i) a visão estratégica de longo prazo do governo chinês; (ii) a 
centralização do processo decisório; (iii) o coordenação entre os diversos instrumentos de política macroeconômica; (iv) a estrutura descentralizada de implementação dos investimentos públicos; (v) a importância dos bancos de desenvolvimento e dos bancos comerciais públicos no mecanismo de transmissão da política monetária; (vi) os controles sobre fluxos de capital e o consequente uso da política cambial como instrumento de desenvolvimento econômico e mudança estrutural.

Em dois momentos cruciais do período recente - nas crises de 2008 e 2020 o governo da China se apoiou no arcabouço institucional existente para a implementação de políticas macroeconômicas anticíclicas, associadas a outras políticas nos campos industrial e comercial. Em ambos os casos, os resultados da política macroeconômica não devem ser tomados isoladamente, mas sim como parte desse arcabouço mais amplo que permite a atuação rápida e bem sucedida.

Deve-se ainda destacar que os resultados de qualquer política macroeconômica são condicionados às expectativas geradas por seu anúncio e à reação dos agentes econômicos. No caso da China, é explicito o papel atribuído ao governo como um guia para as expectativas de mercado. Assim, parte dos bons resultados das ações de política macroeconômica, tanto em 2008 como em 2020, decorre de uma expectativa consolidada de que o governo chinês atuará de forma coordenada e efetiva para uma retomada da atividade econômica, e de que dispõe dos instrumentos adequados para tanto.

Por fim, cabe notar que a reação do governo chinês às crises de 2008 e 2020 não se limitou a combater os efeitos imediatos da desaceleração econômica. Dada sua visão estratégica, o governo buscou - por meio dos investimentos em infraestrutura adequados a cada momento específico - conciliar a recuperação da atividade econômica com a construção de uma trajetória favorável de desenvolvimento a longo prazo. Embora os efeitos das políticas adotadas em 2020 ainda não tenham se concluído, o caminho trilhado até aqui sugere que a China, uma vez mais, apresentará uma recuperação relativamente rápida e que tais políticas ampliarão também as perspectivas de desenvolvimento econômico futuro do país. 


\section{Referências}

Bresser-Pereira, L.C. "Reflexões sobre o Novo Desenvolvimentismo e o Desenvolvimentismo Clássico". Revista de Economia Política, 36(2), pp. 237-265, 2016.

Bresser-Pereira, L.C., Jabbour, E. and De Paula, L. "South Korea's and China's catching-up: a new-developmentalist analysis". Brazilian Journal of Political Economy, 40(2), pp 264284, 2020.

Carvalho, F.C. "Economic policies for monetary economies: Keynes's economic policy proposals for an unemployment-free economy". Revista de Economia Política, 17(4), pp. 31-51, 1997.

Chen, H., Chen, Q. and Gerlach, S. "The implementation of monetary policy in China: the interbank market and bank lending". International Finance Review, Volume 14, p.31-69, 2013.

Funke, M. and Tsang, A. "The People's Bank of China's response to the coronavirus pandemic - a quantitative assessment”. BOFIT Discussion Papers, 12, 2020.

Huang, Yi et al. "Saving China from the Coronavirus and Economic Meltdown: Experiences and Lessons". VoxEU eBook on COVID Economic Policy Response, March 2020. Available at: https://ssrn.com/abstract=3570696

Keynes, J. M. The General Theory of Employment, Interest and Money. London: Macmillan, 1936.

Libânio, G. "People's Bank of China”. In: L. Rochon and S. Rossi (eds). The Encyclopedia of Central Banking. Cheltenham: Edward Elgar, 2015.

National Bureau of Statistics. China statistical yearbook. Beijing: China Statistics Press, 2019.

Naughton, B. The Chinese Economy: adaptation and growth. Cambridge, MA: MIT Press, 2018.

Sun, Q. and Fu, X. "China's battle against the global economic crisis". In: Fu, X. (ed). China's Role in Global Economic Recovery. Abingdon: Routledge, 2012.

Wong, C. "Budget reform in China: Progress and prospects in the Xi Jinping era", OECD Journal on Budgeting, vol. 15/3, p. 1-10, 2016. 


\section{NOTAS DE AUTOR}

CONTRIBUIÇÃO DE AUTORIA

Gilberto Libânio - Concepção. Definição da metodologia. Coleta, organização e análise de dados. Elaboração do manuscrito, revisão e aprovação da versão final do trabalho.

\section{FINANCIAMENTO}

FAPEMIG - Programa Pesquisador Mineiro (Edital PPM X - 2016).

\section{CONSENTIMENTO DE USO DE IMAGEM}

Não se aplica.

\section{APROVAÇÃO DE COMITÊ DE ÉTICA EM PESQUISA}

Não se aplica.

\section{CONFLITO DE INTERESSES}

Não se aplica.

\section{LICENÇA DE USO}

Este artigo está licenciado sob a Licença Creative Commons CC-BY-NC. Com essa licença você pode compartilhar, adaptar, criar para qualquer fim, sem uso comercial e desde que atribua a autoria da obra.

\section{HISTÓRICO}

Recebido em: 02-10-2020

Aprovado em: 04-11-2020 